\title{
Celine Spector, Montesquieu et l'émergence de l'économie politique
}

\section{Paola Salerni}

\section{Q OpenEdition}

1 Journals

\section{Edizione digitale}

URL: http://journals.openedition.org/studifrancesi/9551

DOI: 10.4000/studifrancesi.9551

ISSN: 2421-5856

\section{Editore}

Rosenberg \& Sellier

\section{Edizione cartacea}

Data di pubblicazione: 1 décembre 2007

Paginazione: 660-661

ISSN: 0039-2944

Notizia bibliografica digitale

Paola Salerni, «Celine Spector, Montesquieu et l'émergence de l'économie politique», Studi Francesi

[Online], 153 (LI | III) | 2007, online dal 30 novembre 2015, consultato il 12 janvier 2021. URL: http:// journals.openedition.org/studifrancesi/9551; DOI: https://doi.org/10.4000/studifrancesi.9551

Questo documento è stato generato automaticamente il 12 janvier 2021.

\section{(c) (i) (9)}

Studi Francesi è distribuita con Licenza Creative Commons Attribuzione - Non commerciale - Non opere derivate 4.0 Internazionale. 


\title{
Celine Spector, Montesquieu et l'émergence de l'économie politique
}

\author{
Paola Salerni
}

\section{NOTIZIA}

CELINE SPECTOR, Montesquieu et l'émergence de l'économie politique, Paris, Champion, 2006, pp. 498.

1 Attualissima e determinante per il destino di molti Paesi, la scienza economica affonda le sue origini nel xviii secolo, quando si impose persino sulle dinamiche politiche. L'autrice di questo ponderoso volume ricostruisce con precisione il ruolo avuto da Montesquieu nel considerare l'economia una forma di sapere e non una scienza; il suo scopo è soprattutto investigare in quale modo uno dei maggiori filosofi politici del XVIII secolo, più famoso per la teoria della distribuzione dei poteri e per l'accesa critica al dispotismo, abbia determinato il sorgere delle moderne problematiche - persino in termini di globalizzazione - e soprattutto perché abbia preso in considerazione gli effetti del mercato sulla concezione dello Stato e sulla formazione del citoyen. Montesquieu, sottolinea Celine Spector, ha stabilito i rapporti fra i poteri, le ricchezze e le società moderne. L'Esprit des lois permette di valutare i vantaggi ma di misurare anche i rischi dell'accentramento economico e il conseguente indebolimento della sovranità politica: avendo identificato i motivi positivi dell'economia, ossia il potenziale di emancipazione che racchiude, Montesquieu ha immaginato l'ambivalenza associata alla globalizzazione delle ricchezze e le sue possibili incidenze sul declino dell'etica civile e della libertà politica. La riflessione sulla natura delle ricchezze va di pari passo con quella sull'esercizio del potere: procedendo nell'investigazione allo stesso modo di Kant, non ha preso in considerazione i rischi contenuti tanto nella polarizzazione delle disuguaglianze quanto nell'imperialismo responsabile del sorgere del capitalismo. Avendo comunque previsto che il commercio internazionale avrebbe indebolito le basi della sovranità politica, Montesquieu ha sempre accostato l'economia alla morale e al sociale, ossia ad altre sfere della vita politica attraverso la determinazione delle cause 
fisiche e morali delle leggi e dei costumi, la valutazione dell'utilità delle istituzioni e delle loro realizzazioni specifiche. Nessun fenomeno sociale può essere indipendente dagli altri.

Per assegnare il giusto ruolo al suo pensiero, la studiosa distingue due diversi approcci nella valutazione dell'economia politica: il primo prende in considerazione la sua formazione come scienza e teoria autonoma; la seconda, la sua costituzione come discorso o ideologia. Nel primo caso la scienza economica moderna, collegandosi strettamente con la gestione dello Stato, provoca la rottura concettuale con il pensiero antico e si articola come messa a punto razionale di mezzi e finalità: nel Settecento il lemma commerce (p. 183) pare più pertinente per designare le attività di produzione e di scambio. Nei dizionari dell'epoca rinvia in senso lato a una comunicazione tra gli uomini, alla loro frequentazione nel «commerce du monde» e dei popoli applicandosi sia agli scambi culturali sia a quelli materiali. Solo nell'accezione più restrittiva rinvia allo scambio di beni permettendo la soddisfazione di bisogni, acquisti e vendite per realizzare profitti. In questa prospettiva lo studio del commercio, pur non ancora costituitosi in scienza autonoma, porta a valutare le fonti della ricchezza della nazione e a scoprire i mezzi con i quali l'arricchimento dei privati determina quello dello Stato. Avvalendosi del supporto di numerosissimi apporti critici, la studiosa si prefigge di individuare il punto in cui convergono i due tracciati: la scoperta delle sue leggi e postulati, ma anche la formazione dell'ideologia capitalistica o l'apologia della società che ne deriva. Nella sua opera maggiore la riflessione sul potere effettuata dal filosofo chiarisce i rapporti fra l'economia e la pace, contro la finanza associata alle pratiche assolutistiche e alla logica di guerra. A causa della sua mobilità, il commercio può, quindi, porsi come limite alla tendenza dispotica delle monarchie corrotte, perché costituisce un ostacolo all'estensione del potere del re evidenziando l'utilità della moderazione.

3 Celine Spector non tralascia neppure l'interesse per la funzione della moneta contante, anch'essa responsabile delle condizioni politiche affermandosi come misura, garanzia ed equivalente universale negli scambi: per questa ragione il legislatore deve garantire una certa stabilità monetaria quale struttura favorevole alla nascita dei confronti finanziari. La questione della "population" costituisce un altro aspetto dell'analisi dell'accumulo della ricchezza, in particolare per quanto riguarda il dato demografico. Mentre le considerazioni economiche delle Lettres Persanes e de L'Esprit des lois conosceranno un debole successo, la tesi dello spopolamento del mondo sarà invece discussa da coloro che desidereranno riformare la monarchia francese, ritenuta responsabile del suo declino. Lo scopo è l'identificazione del circuito produttivo ponendo in questo modo l'accento sull'incapacità dell'amministrazione francese di eseguire i censimenti e sul ruolo eminentemente politico del dato demografico - poiché la popolazione è il maggior fondo produttivo delle ricchezze: del resto Richelieu era ben consapevole che la preoccupazione economica e militare coesistevano. Mentre Francia e Inghilterra si occupavano di controllare la natalità e la mortalità, indici della situazione sanitaria della popolazione, la Germania aveva messo a punto una vera police médicale consacrata al miglioramento della longevità e della condizione di salute pubblica, manovra strategica che riconosceva la società quale luogo di benessere fisico. Di fondamentale importanza quindi proteggere la crescita delle forze produttive e l'ottimizzazione delle condizioni di vita. Il rapporto fra demografia e lusso costituirà, del resto, un motivo di disaccordo prima con Quesnay e poi Ferguson, Adam Smith e 
Rousseau, quest'ultimo animato da obiettivi repubblicani. Dopo aver preso in considerazione anche l'idea dell'attività agricola come fonte della dinamica produttiva delle monarchie moderne e del lavoro come emancipazione dall'uomo dalle costrizioni della natura, lo studio si conclude sul commercio coloniale, che produce ricchezza multiforme e mobile. La delocalizzazione permette di affrancarsi dallo spirito di conquista che conduce al dispotismo; la circolazione di uomini e capitali, la loro «fluidité» (p. 400), portano pace e libertà politica oltre le frontiere, smantellando i privilegi dei nobili o delle città considerate i bastioni della centralizzazione e dell'assolutismo. Suscitando, quindi, problematiche di grande interesse e attualità, il profondo e capillare scandaglio effettuato da Celine Spector dimostra e conferma la modernità di Montesquieu. 